\title{
Trade Costs, Export Development and Poverty in Rwanda
}

\author{
Ndiame Diop ${ }^{\mathrm{a}}$, Paul Brenton ${ }^{\mathrm{a}}$ and Yakup Asarkaya ${ }^{\mathrm{b}^{*}}$
}

\begin{abstract}
For Rwanda, one of the poorest countries in the world, trade offers the most effective route for substantial poverty reduction. However, the poor in Rwanda, most of whom are subsistence farmers in rural areas, are currently disconnected from markets and commercial activities by extremely high transport costs and by severe constraints on their ability to shift out of subsistence farming. The constraints include lack of access to credit and lack of access to information on the skills and techniques required to produce commercial crops. The paper is based on information from the household survey and a recent diagnostic study of constraints to trade in Rwanda. It provides a number of indicative simulations that show the potential for substantial reductions in poverty from initiatives that reduce trade costs, enhance the quality of exportable goods and facilitate movement out of subsistence into commercial activities.
\end{abstract}

World Bank Policy Research Working Paper 3784, December 2005

The Policy Research Working Paper Series disseminates the findings of work in progress to encourage the exchange of ideas about development issues. An objective of the series is to get the findings out quickly, even if the presentations are less than fully polished. The papers carry the names of the authors and should be cited accordingly. The findings, interpretations, and conclusions expressed in this paper are entirely those of the authors. They do not necessarily represent the view of the World Bank, its Executive Directors, or the countries they represent. Policy Research Working Papers are available online at http://econ.worldbank.org.

\footnotetext{
* a Trade Department, World Bank. ${ }^{\text {b}}$ University of Virginia. We would like to thank Ataman Aksoy, John Baffes, Kene Ezemenari and Waly Wane for helpful comments and Yakup Asarkaya for research assistance.
} 


\section{WPS3784}

\section{Introduction}

Rwanda is one of the poorest countries in the world, with a per capita income of \$230 in 2003. The vast majority of the poor reside in rural areas so that rural development is crucial to sustained poverty reduction. The majority of the poor are farmers and the poorest are those that produce mainly or solely for subsistence. Farmers involved in the production of commercial crops, primarily tea and coffee, tend to be less poor and have a high propensity to spend on other products produced in rural areas. Given its small domestic market, it is trade that offers the best prospect of sustained growth and poverty reduction. But at present, handicapped by extremely high trade costs, Rwanda's rural economy is trapped in subsistence activities. Annual exports per capita in Rwanda amount to just \$18 compared to an average of \$145 in Sub-Saharan Africa.

This paper shows how opening up rural Rwanda to commercialization and trade could have a substantial impact on poverty. Three major interrelated routes by which trade can enhance rural incomes, unleash the potential for specialization and reduce poverty are analyzed. First, reducing rural transport costs is central to initiate a strong growth impulse through higher farm gate prices for exportables and more specialization in commercial products. We highlight this issue by concentrating on coffee, the principal agricultural export. Transport costs facing producers in Rwanda are very high and many farmers are effectively delinked from national and international markets. High transport costs depress farm gate prices and represent an implicit tax on exportable producers. Second, a key element of the Rwanda government's strategy for the coffee sector, as well as for other commercial crops, is to increase quality through a fully washed strategy. Fully washed coffee has been commanding prices that are more than double that of standard coffee. Finally, reducing transport costs and the introduction of quality-enhancing techniques will increase the incentives for rural households to participate in the production of exportable products. We assess the impact on incomes and poverty of successful switching of the poorest farmers into higher return economic activities.

Our analysis, based on information from the 2001 household survey, suggests that all three mechanisms have a very strong potential for reducing poverty in Rwanda, with 
particularly strong impacts on small farms which support the poorest households. For example, facilitating the shift out of subsistence into coffee production for those farmers that have a propensity to produce coffee would reduce the national poverty headcount index by more than a quarter. However, substantial barriers to rural development will constrain movements out of subsistence into commercial production. The key barriers are the lack of availability of credit in rural areas to finance the transition and lack of knowledge of relevant techniques for cultivating and preparing new crops. While these constraints remain and transport costs are high the poverty reducing potential of trade in Rwanda cannot be realized. Rwanda is severely constrained in addressing these structural barriers, which should be a focus of assistance from the international community.

The rest of the paper is organized as follows. The next section analyzes the main determinants of poverty in Rwanda, emphasizing the role of trade costs. Sections 3 and 4 examine the impacts of lower transport costs and higher quality coffee on poverty, respectively. Section 5 looks at the structural implications of those two simulations on the rural economy. It highlights the poverty impact of switching from subsistence to more commercial agriculture and open trade. The main policy implications and conclusion are drawn in section 6 .

\section{Trade Costs as Key Determinants of Poverty in Rwanda}

The first step in putting in place policies and programs to reduce poverty is to gain an understanding of its key determinants. We investigate here the role of trade costs, among other key determinants, in allowing individuals to escape poverty in Rwanda. To do this, we estimate the determinants of the probability of not being poor in Rwanda through a probit regression, using the Rwanda Household Living Conditions Survey (EICV). The EICV was carried out between October 1999 and July 2001 and it contains community characteristics indicators together with information from 6,420 households distributed among Rwanda's 12 provinces. ${ }^{1}$ The overwhelming majority of the households interviewed live in rural areas, where the incidence of poverty is highest. Indeed, the

\footnotetext{
${ }^{1}$ The sample design contains three main strata: (i) rural prefecture; (ii) urban Kigali and (iii) other prefecture urban centers. The rural prefecture stratum is further subdivided into 11 sub-strata corresponding to each rural prefecture.
} 


\section{WPS3784}

headcount index in rural Rwanda stands at 47 percent, against only 13 percent in urban $\operatorname{areas}^{2}$ (Table 1). The EICV also shows that poverty varies substantially across provinces. The poverty incidence is highest in Gikongoro (57 percent) and lowest in Kigali Ville (10 percent).

Denoting $y$ as the poverty status (incidence index) of observed individuals within the sample, and $X$ as a vector of major individual, household, community and regional characteristics, the probability of escaping poverty is defined by the probit model:

$\operatorname{Pr}(y=1 \mid X)=\Phi(X b)$

$\Phi$ is the standard cumulative normal probability distribution and $X b$ is the probit score or index. The probit coefficient, $b$, shows the impact of a one-unit increase in the predictor on the probability of not being poor. A one-unit increase in the predictor leads to an increase in the probit score by $b$ standard deviations. We model the probability of being out of poverty as a function of the following predictors: market access community variables (such as, access to roads, access to electricity, proximity of markets), household and individual characteristics (demographic profile, head of household education, land size, livestock, etc.), and a set of control variables such as provincial dummies.

Table 2 shows the results of the probit estimation. A key feature of these results is the central role of community variables in escaping poverty. Access to year-round roads, credit and electricity increase significantly the chances of escaping poverty. Of particular interest in the context of this paper is that all of the market access variables significantly influence the chance of escaping poverty. Households that do not have easy access to a road and/or have to use impracticable earth roads to connect to secondary or main roads have limited or no access to product and factor markets, substantially reducing the opportunities for escaping poverty. Regional disparities in the probability of being poor partly reflect this result. Residents of Kibuye, Kigali, Gikongoro, Byumba, and Butare that are more likely to be in poverty have poor access to community infrastructures, rural

\footnotetext{
${ }^{2}$ For our analysis the poverty line is conventionally defined as the per capita income of the final individual in the $4^{\text {th }}$ decline of the income distribution. The headcount index, P0, is the proportion of population with per capita expenditure below the poverty line. The poverty-gap, P1, estimates the average distance separating the poor from the poverty line, as a proportion of that line.
} 
transport in particular. In contrast, residents of Gisenyi and Kibungo, better endowed in infrastructures, are more likely to be out of poverty.

Among the household characteristics that affect poverty, occupation appears to be the single most important variable. The results suggest that someone who earns a wage in the non-farm sector has a substantially higher chance of not being poor and that a selfemployed non-farm worker is also much more likely to be non-poor. On the other hand, being an agricultural worker (4 percent of rural households) implies a higher probability of being poor. However, these three categories represent only 4 and 8.5 percent of rural households, respectively. About 76 percent of household heads are farmers. Being a farmer helps many households escape from poverty but only insofar as the comparator category is households without occupation (7 percent are in other sectors or have no occupation). ${ }^{3}$

The other household characteristics that significantly affect poverty include household size, education and the level of wealth, reflected in terms of land and livestock holdings. Households with a low dependency ratio, large land and livestock holdings and a more educated head are more likely to be out of poverty. The result regarding land is interesting given a proposed revision to the land law in Rwanda that seeks to increase the feasibility of larger land plots. Also of importance here is the role of cooperatives, which can successfully bring small scale farmers together to allow for more efficient utilization of land, improved access to credit and better dissemination of information. The key message here is that a reorganization of the rural sector, which leads to the more effective use of agricultural land, is likely to have a substantial effect in reducing poverty.

\section{The Poverty Impacts of Lower Rural Transportation Costs}

\section{Direct short run narrow effects}

The analysis in this section shows that allowing and improving access to markets through better rural infrastructure, especially rural transport, has a strong potential for reducing

\footnotetext{
${ }^{3}$ These results are consistent with those of Dabalen, Paternostro and Pierre (2004) on the returns to participation in the nonfarm sector in Rwanda.
} 
poverty. ${ }^{4}$ The analysis concentrates on coffee, the main exportable crop and the main vehicle for raising cash incomes in rural areas and for stimulating a switch from subsistence to more market oriented agriculture. Beyond coffee farmers, reductions in rural transport costs will benefit all producers and consumers in rural areas and will be integral to a policy that seeks to increase the role of markets and market oriented production in rural areas. Thus, the impact of policy and investment initiatives to improve access to rural transport will by far exceed the more narrow simulations on poverty that we investigate here.

As a small coffee exporter, Rwanda is a price taker in the world markets. Hence in the analysis below we take world prices as exogenous and assume that changes in coffee supply in Rwanda have no impact on the world price. For all coffee farmers, regardless of the quality of their crop, one of the key determinants of the producer price that they receive in Rwanda will be the transport cost.

Transport costs incurred by exporters both within Rwanda and on the main corridor routes to ports in neighboring countries are very high. It is estimated that the transport cost from the farm-gate in Rwanda to the port in Mombassa is about 80 percent of the producer price. Rural transport costs alone, that is, of transport from the farm gate to the capital, Kigali, is estimated at 40 percent of the farm gate price $!^{5}$ These costs represent an implicit tax on coffee (and other exportable) producers.

Porto (2005) shows how reducing trade costs in Moldova could have a substantial impact on poverty. We follow a similar approach simulating lower rural and international transport costs leading to higher prices for farmers, which encourage greater production and raise the incomes of rural farmers. Here, we look specifically at the effect of a 50 percent cut in rural transport costs on coffee farmers’ income. This is not unrealistic. Most of the roads in rural areas are unpaved. Vehicle operating costs are estimated to be

\footnotetext{
${ }^{4}$ Access to rural transport is also a key element in providing access to other key services related to poverty and standards of living, such as, participation in education and access to health services.

${ }^{5}$ World Bank (2005)
} 


\section{WPS3784}

about 50 per cent higher on poor quality roads compared to good quality roads. ${ }^{6}$ For many farmers roads are not accessible or totally inadequate and head carrying is the only available mode of transport. Given the uncertainty of the magnitude of such a reduction in transport costs on producer prices, we perform the simulations using two pass-through assumptions that is the extent to which the fall in transport costs is reflected in higher producer prices for farmers: a 100 percent pass-through and a 50 percent pass-through.

We follow Deaton $(1989,1997)$ whereby the short-run effects of price changes are directly proportional to income shares. In particular, holding all the other components of household income constant and assuming that coffee produced in Rwanda is entirely exported (there is almost no domestic consumption of coffee), the direct short-term welfare impact of a price shock on household $i$ is given by:

$$
\left(\frac{\Delta Y}{Y_{0}}\right)_{i}=\phi_{i}^{\text {coffee }} *\left(\frac{\Delta P^{\text {coffee }}}{P_{0}^{\text {coffee }}}\right)
$$

Where $Y_{0}$ is initial income of household $i, \Delta Y$ is the change in income following a change in the price of coffee, $\phi_{i}^{\text {coffee }}$ is the share of coffee income (sales) in total household income as provided by the EICV survey and $P_{0}^{\text {coffee }}$ the initial average producer price of coffee.

Table 3 shows the different sources of income for Rwandan households, including income derived from coffee sales. At the national level, close to 57.6 percent of households' income comes from labor market activities and almost 26 percent of income is derived from the sale of agricultural products. In rural areas, agricultural income accounts for close to 42 percent of total income, most of which is derived from the sale of food crops (33 percent) while a smaller portion comes from the sale of commercial crops,

\footnotetext{
${ }^{6}$ A World Bank study found that lack of maintenance on the road between Gitarama and Kibuye raised vehicle operating costs from a 1989 level of \$1.00 per kilometer to almost \$3.40 per kilometer in 1996. The recent rehabilitation of the road has resulted in a fall of more than 50 percent in vehicle operating costs and to a reduction of overall transport costs of about 40 percent. As a result, agricultural surpluses in the area can now be sold in markets throughout the country, and a general shift is taking place from subsistence agricultural to production for the market (World Bank (2005)).
} 


\section{WPS3784}

mainly from the sale of coffee ( 3 percent). Labor market income constitutes about 43 percent of the income of rural households, but agriculture contributes little to this (8 percent), most of the income coming from collective services (16 percent).

Since the direct effect of an increase in the farm gate price of coffee is on coffee farmers, we restrict the sample to coffee growers (those that produce a nonzero quantity of coffee in the year before the administration of the questionnaire). This allows us to see more clearly the contribution of coffee to the total income of a group that represents 10 percent of rural households and about 400,000 people. The share of income derived from coffee varies between 14.4 percent for coffee farmer households in the $4^{\text {th }}$ decile and 1.79 percent for the top decile (table 4). Due to different agro-ecological conditions and infrastructure availability across regions, there is a wide disparity in households' ability to engage in coffee production and, therefore, in the contribution of coffee to total income. The share of coffee sales in total income is the greatest in Cyangugu province with 14 percent, while coffee is not a viable option in Umutara and represents a minor activity in Ruhengeri and Buyamba (table 5).

Table 6 shows the results of the simulations. A 50 percent reduction in rural transportation costs that translates into a 20 percent increase in coffee producer prices reduces the poverty incidence among coffee farmers by almost 6 percent (from 42 to 39.6 percent), and the poverty gap of coffee farmers by 7 percent (from 0.136 to 0.126$)^{7}$. This corresponds to about a half percent reduction in national poverty incidence, or about 16400 people $^{8}$. This reduction in the number of poor is not trivial given that no secondround effect is incorporated in the analysis (see below). The impact of reductions in transport costs on coffee farmers' incomes is fairly linear, smaller or larger changes in transport costs will have proportionate effects on incomes. Here we have assumed a 50 percent fall in rural transport costs alone. If international transport costs were also to fall by a similar magnitude the impact on coffee farmers incomes would be approximately

\footnotetext{
${ }^{7}$ As a starting point, note that coffee farmers are located in the middle section of the income distribution. They are neither extremely poor nor rich. Their poverty gap for coffee producers is of less than 0.14 against 0.16 for non-coffee farmers also clearly indicates that poverty is less deep among coffee farmers than noncoffee farmers.

${ }^{8}$ Calculated as: $0.0053 * 0.43 * 7,200,000$.
} 


\section{WPS3784}

double that presented in table 6 . There is substantial potential for lower transport costs on the main trade routes. It is estimated that the cost per ton of transport between Mombasa and Kigali can be more than 70 percent higher than the cost of transport between Mombasa and Kampala (World Bank 2005).

Furthermore, reducing rural transport costs has a positive impact on the distribution of income - the poor benefit (those in the first four deciles) proportionally more than their wealthier counterparts (table 7). The effect on the distribution of income (ranked in deciles) mirrors the distribution of the share coffee income in total income. Coffee farmers in the $4^{\text {th }}$ decile, for whom coffee provides 14 percent of total income, would see a 3 percent rise in their income. In contrast, coffee farmers at the top of the income distribution would only enjoy a 0.36 percent increase in income. In terms of the different regions, the largest welfare gain accrues to Cyangugu (+2.7 percent), Kigali Ngali $(+1.8$ percent) and Kibuye ( +1.8 percent) whilst in regions where coffee is less important as a source of income, Umutara, Ruhengeri and Buyamba, there is little increase in income (table 7).

Potential second-round effects.

While the direct effect of changes in coffee producer prices falls on the welfare of coffee farmers, other farmers and non-farmers may reap significant indirect benefits from higher coffee incomes. The two traditional channels through which spillover effects work are through the labor market and the markets for food and other local non-farm goods. In Rwanda, only 8 percent of coffee farmers employ paid labor, implying that greater returns to coffee farming may have little employment impact in the short run.

Furthermore, since farmers use sub-optimal levels of fertilizer, they may be more inclined to use some of their extra income to apply more fertilizer and boost productivity, rather than increasing employment. Finally, given Rwanda's very high labor to land ratio (with a population density of 350/ km2), a land constraint may prevent high incremental employment while at the same time, a large pool of landless people may suppress the potential increase in wage rates (in other words, it is unlikely that a neoclassical closure rule --full employment and flexible wage rate- applies in rural Rwanda). 
In contrast, significant spending spillover effects are likely to arise from the higher incomes for coffee farmers. On average, some 40 percent of coffee farmers' income is spent on food products. The share of income spent on food is actually higher is some regions, mirroring the geographical disparities in coffee production in Rwanda. Food expenditures have the highest share in consumption in Cyangugu and Kibuye, accounting for about 54 percent of total consumption and the lowest share in Umutara and Kibungo, with 38-40 percent (table 8). The marginal spending of extra incomes on local goods and services can have strong multiplier effects in the rural economy, especially in Cyangugu and Kibuye ${ }^{9}$. Given the constraint on land however, provinces where a growing number of farmers engage in producing exportable crops will increasing rely on other regions and the international market for their food and other goods imports. Once again lower transport costs are important, as is an open trade regime ${ }^{10}$, to reap the benefits of specialization.

\section{The Poverty Impacts of Higher Quality Coffee}

Enhancing the quality of agricultural products produced in Rwanda's rural economy is another vehicle for poverty reduction. A key element of the government's strategy for the coffee sector is to increase the proportion of washed or quality coffee in output and exports. Fully washed coffee has been commanding prices that are more than double that of standard coffee. Here we investigate the potential impacts of this strategy on poverty. It is worth noting that improvements in rural transport logistics are crucial to the success of the fully washed coffee strategy since the coffee cherries must be washed within 6 hours of being harvested or the quality starts to depreciate. Clearly farmers that are currently more than 6 hours distant from a washing station will be unable to benefit from this strategy.

\footnotetext{
${ }^{9}$ The magnitude of multiplier effects depends on supply elasticities of local goods, as demonstrated by Delgado et al. (1998), after Haggblade et al. (1991). If capital constraints or high transaction costs result in inelastic supply of non-tradable goods, then costs of production will quickly rise with expanded demand, and the growth in production of local goods and services will be dampened.

${ }^{10}$ For example, tariffs on imports of rice are currently high at more than 25 percent.
} 
Using the same methodology as above, we explore a number of scenarios. First, we simulate the impact of half of coffee farmers receiving double the price for their coffee as a result of producing higher quality coffee. Second, we assess the impact when only large farms are able to increase quality and receive double the price for their coffee, whilst the third simulation constrains the impact of higher quality to medium sized farms. Next, we allow for both large and medium farms to receive the 100 percent price increase for higher quality coffee. A final scenario assumes that only small farms raise quality and receive double the price for their coffee. Small farms are defined as farms with less than 0.5 hectare, medium sized farms are those with between 0.5 and 1 hectare, while large farms have more than 1 hectare.

The results suggest that the coffee quality program has a strong poverty-reducing potential. For instance, doubling the price received by half of coffee farmers reduces the incidence of national poverty by about 5 percent (table 9). Further, the poverty impact of the quality program is inversely proportional to the level of income. Targeting small farms, through technical assistance and access programs, could reduce the incidence of national poverty by 6 percent, compared to a reduction of 2 percent if only large farms adopt the quality program. This reflects that most of the large farmers are not poor. On the other hand, they are more capable of adopting the quality program and their resulting increase in income could indirectly benefit the poorest farmers.

\section{Welfare Gains from Switching from Subsistence to Coffee Farming}

Lower transport costs and the introduction of quality-enhancing techniques will boost the incentives to produce coffee in Rwanda. Existing farmers will seek to raise productivity and will be better able to purchase fertilizer and invest in new coffee trees and improved techniques. Higher returns to coffee will also lead to an increase in the number of farmers who wish to switch from subsistence to coffee production. In this section, we explore the potential gain to farmers from switching from subsistence agriculture to coffee farming in Rwanda and then assess the impact on national poverty if such switching were to occur. The purpose of this analysis is to stress that initiatives to reduce transport costs and raise 


\section{WPS3784}

the quality of exported crops will have a much greater impact and return if constraints to farmers moving out of subsistence and into commercial crops are also addressed.

To do this analysis, one cannot just compare the average observed income of coffee farmers with that deduced for subsistence farmers since these two groups of farmers have different characteristics, some of which are correlated with the probability of belonging to one or other category. It is important to take into account the propensity of farmers to move out of subsistence and into coffee production. Here this is based on the characteristics of those already producing coffee.

The propensity score matching (PSM) methods, pioneered by Rubin (1977), Rosembaun and Rubin (1983), and Heckman, Ichimura and Todd (1997), allow one to build a counterfactual and estimate the average effects of participating in coffee markets on monetary household incomes. In other words, they help determine how much extra income is associated with switching from subsistence to coffee, assuming a binding land constraint. The method consists of first estimating the probability of producing coffee (probit model) that defines a propensity score $\mathrm{p}(\mathbf{x})$, for a given vector of observable characteristics $\mathbf{x}$. In a second stage, one can use either traditional (one-to-one) or more recent matching methods to pair participants (coffee farmers) and non-participants (subsistence farmers). Traditional PSM methods (Rubin 1977, Rosembaun and Rubin 1983) pair each participant with a single non-participant, the matching being based on the degree of similarity in the estimated probabilities of being a participant. More recently developed non-parametric matching estimators use a weighted average over multiple observations to construct the matches (see Heckman et al, 1997). We apply both methods in this analysis. Finally, the outcome differential, here the per capita income gain, is estimated using kernel methods.

More formally, denote $Y_{1}$ the outcome (income) conditional on participation in coffee farming and $Y_{0}$ the outcome conditional on non-participation. The impact of participation is

$$
\Delta=Y_{1}-Y_{0}
$$


Let $D=1$ for individuals who participate and for whom $Y_{1}$ is observed and $D=0$ for non-participants, for whom $Y_{0}$ is observed. Finally let $\mathrm{Z}$ denote a vector of observed characteristics of individuals used as conditioning variables. Our task is to estimate the mean impact of participation ("the mean treatment effect on the treated"), given by:

$T T=E(\Delta \mid Z, D=1)=E\left\{\left(Y_{1}-Y_{0}\right) \mid Z, D=1\right\}=E\left(Y_{1} \mid Z, D=1\right)-E\left(Y_{0} \mid Z, D=1\right)$

The parameter $T T$ estimates the average impact among participants. However, while observed data on $Y_{1}$ allows a computation of $E\left(Y_{1} \mid Z, D=1\right)$, the counterfactual mean, $E\left(Y_{0} \mid Z, D=1\right)$, cannot be directly estimated, hence the recourse to matching estimators. Denoting P, the propensity score, i.e., the probability of participation given $\mathrm{Z}$, $P=\operatorname{Pr}(D=1 \mid Z)$, one key assumption made is:

$E\left(Y_{0} \mid P, D=1\right)=E\left(Y_{0} \mid P, D=0\right), \quad P<1$

In other words, the outcome for non-participants matched to participants using the closeness of their propensity score (characteristics) is a proxy for the outcome for participants had they not participated.

The mean impact of participation thus becomes ${ }^{11}$ :

$\phi_{p}=E\left(Y_{1} \mid D=1\right)-E_{P \mid D=1}\left\{E_{Y}(Y \mid D=1, P)\right\}=E\left(Y_{1} \mid D=1\right)-E_{P \mid D=1}\left\{E_{Y}(Y \mid D=0, P)\right\}$

Applying this method to our purpose, $\phi_{P}$ is the average extra income that an individual would gain from switching from subsistence to coffee farming.

To model the decision to engage in coffee farming, we build on the large literature on the determinants of adoption of new techniques in agriculture (Foster and Rosenzweig 1995,

\footnotetext{
${ }^{11}$ For an in-depth discussion of the matching techniques and assumptions, see Smith and Todd (2001).
} 


\section{WPS3784}

Conley and Udry 2004, Besley and Case 1994). This literature identifies human capital (measured by education, gender, and age), learning by doing and learning externalities as major determinants of technology adoption. We model the decision to engage in coffee farming as a function of market access community variables, household characteristics (head of household education, demographic profile, level of wealth, etc.), and a set of control variables such as provincial dummies and availability of extension services. The probit regression is performed for heads of households. The switch from subsistence to coffee can be interpreted as technology adoption in agriculture.

Community characteristics strongly influence the probability of participating in coffee farming with access to electricity, road and extension services all being important (table 10). Extension services are a set of technical supports, training and information about markets provided to farmers to increase productivity and profitability through the promotion of new crops, new techniques and new quality-enhancing practices. Other studies on African economies also show the importance of extension services. For instance, Balat et al. (2004) find that households in Zambia that have received extension services are on average more productive in market agriculture than households that have not. Clearly, provision of high-quality extension services is central to facilitating a structural transformation of agriculture in Rwanda.

Demographic profile is the most important household characteristic that significantly influences the likelihood of engaging in coffee farming. Households with many dependents and headed by a male are more likely to be involved in coffee farming in Rwanda. Coffee is a labor-intensive activity and in a situation where labor markets are imperfect, having a large pool of family labor appears to be an advantage. This is important because our earlier broad analysis of the determinants of poverty showed that a high number of dependents is positively associated with the probability of being poor. This suggests that, after controlling for community characteristics, those households currently involved in subsistence activities who have a relatively strong propensity to produce coffee are more likely to be poor. Hence, initiatives that facilitate the movement 
of these households into coffee production are likely to have a very strong impact on poverty.

Education and land and livestock holdings affect positively the probability of participating in coffee farming. This is not surprising. Engaging in a tradable sector presents different challenges to farmers, compared to those that arise in producing nonmarketable products. These include substantial initial investments, the capacity to adjust to frequent changes in prices as well as adoption of new technologies and marketing skills, all of which are helped by education and wealth reflected in terms of land and livestock. ${ }^{12}$ Thus, in the absence of effective financial markets in the rural area, it is only relatively wealthy farmers who have the capacity to move into coffee production. Finally, agro-ecological conditions are an important endowment for some provinces and districts (Cyangugu, Butare, Gitarama) and a serious constraint to engaging in coffee farming for others (Umutara, Ruhengeri and Buyamba). Farmers in the latter provinces are less likely to gain from a switch from subsistence to coffee farming because of natural constraints.

Having examined the main determinants of the probability of being able to participate in coffee farming, we now look at the potential gain from participating in coffee farming by estimating the average agricultural income subsistence farmers would have earned had they participated in coffee production. We find that farmers who have a propensity to produce coffee who actually shift out of subsistence agriculture into coffee production would have earned between 17,000 and 22,000 RwF more (depending on the particular matching method that is used). This translates into a difference in income of between 23 and 30 percent (table 11). ${ }^{13}$ If the subsistence farmers identified as having a propensity to produce coffee (40 percent of our sample) actually shifted into coffee production then the national poverty headcount index would fall by more then 25 percent and the poverty gap would drop by 12-13 percent.

\footnotetext{
${ }^{12}$ Access to credit did not appear significant in the regression, but this is very likely to relate to how this variable was defined in the questionnaire. The question asked is whether credit is available in the community without precision of the type of credit (micro-credit, credit for farm investment, etc.).

${ }^{13}$ Balat and Porto (2005) find similar quantitative effects in Zambia, where a shift out of subsistence into cotton production leads to gains of around 20 percent of average expenditure for the representative poor farmer.
} 


\section{WPS3784}

These average gains are substantial and raise the question of why farmers are not already making this shift if there is a strong incentive in terms of higher incomes. There must be constraints which are preventing farmers in rural areas from moving away from subsistence agriculture even though they have a propensity to produce coffee. There are a number of issues here that must be addressed including the costs that are incurred in shifting into coffee, in terms of the investment in plants and so on, the lack of income whilst the new plants become harvestable, and the higher risks associated with cash crops. Cadot et al (2005) suggest that these adjustment costs can be very large. They estimate that the cost of moving out of subsistence for farmers in Madagascar can amount to around 250 percent of the value of a subsistence farmer's annual production. These costs and investments all necessitate the effective provision of credit to rural communities, something which is severely lacking at present. In addition, there is also the need for information on techniques for producing different crops, and so a need for widely available extension services, as well as access to transport. 


\section{WPS3784}

\section{Policy Implications and Conclusions}

Increasing incomes in rural areas is necessary for poverty reduction in Rwanda since the majority of the poor live in rural areas. Improvements in returns to exportable commercial crops are the most direct and probably the most effective way of increasing the flow of cash into rural areas and so must lie at the heart of poverty reduction in Rwanda. This paper has shown that reducing trade costs can have a profound impact on poverty. The benefits of lower transport costs, if reflected in higher producer prices, will be realized by all coffee farmers, and indeed all commercial farmers. Reducing transport costs and providing access to transport to those who are currently remote is therefore a crucial element in the poverty reduction strategy. Similarly, our analysis shows that the government's strategy of increasing returns by raising quality and therefore the market price of Rwandan produce will have a significant impact on poverty, particular if small farmers are targeted and assisted in improving the quality of their coffee crop. However, the success of this strategy requires effective rural logistics services and transport capacity, to ensure that coffee is washed in good time before its quality starts to deteriorate. This capacity is currently lacking.

We also show the substantial impact on poverty that could arise if higher returns to commercial crops encourage larger numbers of farmers to shift from subsistence activities into the production of coffee or other commercial crops. We find that a key characteristic linked to the probability of being poor in the overall sample, a large dependency ratio, is associated with a strong propensity to produce coffee. This suggests that measures that facilitate switching into coffee will have an especially strong impact on the incomes of the poorest families in rural areas. Nevertheless, there are substantial barriers to this process of switching into commercial crops in terms of access to credit to finance the adjustment away from subsistence and access to knowledge and skills to successfully cultivate commercial crops. Unless these are addressed, the role of trade in reducing poverty in Rwanda will be severely hampered.

We have found significant impacts on poverty while only considering the most direct reactions to changing prices. However, the effects will be considerably larger, since 


\section{WPS3784}

coffee farmers typically have a high propensity to spend on other products produced in the rural communities. Increasing returns to commercial farmers could have substantial multiplier effects within rural communities. The challenge is to provide an infrastructure and framework by which rural markets can develop and flourish. Given the current level of development in Rwanda it is clear that this will require a significant response and engagement from the international institutions and donors.

\section{References}

Balat, J. and G. Porto (2005) 'Globalisation and Complementary Policies: Poverty Impacts in Rural Zambia’, NBER Working Paper 11175.

Besley, T. and A. Case (1994). "Diffusion as a Learning Process: Evidence From HYV Cotton,” mimeo, Princeton University.

Cadot, O., L. Dutoit and M. Olarreaga (2005) 'Subsistence Farming, Adjustment Costs and Agricultural Prices: Evidence from Madagascar’, mimeo, World Bank.

Conley, T. and C. Udry (2004). "Learning About a New Technology: Pineapple in Ghana,” mimeo, Yale University.

Dabalen A., S. Paternostro and G. Pierre (2004). "The Returns to Participation in the Nonfarm Sector in Rural Rwanda” World Bank Policy Research Working Paper 3462.

Deaton A. (1989). Rice prices and Income Distribution in Thailand: A non parametric Analysis”. Economic Journal 99 (395) (supplement), 1-37.

Deaton, A. (1997). The Analysis of Household Surveys. A Microeconometric Approach to Development Policy, The World Bank and The Johns Hopkins University Press.

Delgado, C. J. Hopkins, and V. Kelly (1998). Agricultural Growth Linkages in SubSaharan Africa. Research report 107, IFPRI.

Foster, A. and M. Rosenzweig (1995). "Learning by Doing and Learning from Others: Human Capital and Technical Change in Agriculture,” Journal of Political Economy, 103, 1176-1209.

Haggblade S, J. Hammer and P. Hazell (1991). "Modelling Agricultural Growth Multipliers”, American Journal of Agricultural Economics, 361-378.

Heckman, J., H. Ichimura, and P.E. Todd (1997) "Matching as an Econometric Evaluation Estimator: Evidence from Evaluating a Job Training Program." Review of Economic Studies, 64, 605-654. 


\section{WPS3784}

Porto, G (2005) 'Informal Export Barriers and Poverty', Journal of International Economics, 66, 447-470

Rosenbaum, P., and D. Rubin (1983). "The Central Role of the Propensity Score in Observational Studies for Causal Effects,” Biometrika, 70, 41-55.

Rubin D. (1977) “Assignment to a Treatment Group on the Basis of a Covariate,” Journal of Educational Statistics, 2, 1-26.

Smith, Jeffrey and Petra Todd. 2001. "Reconciling Conflicting Evidence on the Performance of Propensity Score Matching Methods,” American Economic Review Papers and Proceedings, 91, 112-118.

Winters L.A.; McCulloch N.; McKay A. (2004) "Trade Liberalization and Poverty: The Evidence So Far” Journal of Economic Literature; 42, 72-115.

World Bank (2005). Rwanda: Diagnostic Trade Integration Study. May 2005. The World Bank. 
Table 1. Poverty Incidence and Poverty Gap in Rwanda

\begin{tabular}{lcc}
\hline & Headcount Index (\%) & Poverty Gap \\
& P0 & P1 \\
\hline National & 42.92 & 0.16 \\
Urban & 4.09 & 0.01 \\
Rural & 46.06 & 0.17 \\
\hline
\end{tabular}

Note:

1. The headcount index, $\mathrm{P} 0$, is the proportion of population with per capita expenditure below the poverty line

The poverty-gap, $\mathrm{P} 1$, estimates the average distance separating the poor from the poverty line, as a proportion of that line

2. Poverty line: 50,145.73 RwF = Income per capita of the last individual in the fourth decile of expenditure ranked by adult equivalent

3. All farm households in urban provinces are considered as "rural"

Table 2. Determinants of the Probability of being non-poor in Rwanda

\begin{tabular}{|l|c|c|c|c|c|c|}
\hline & Estimate & $\begin{array}{c}\text { Standard } \\
\text { Error }\end{array}$ & $\begin{array}{c}\text { Wald 95\% Confidence } \\
\text { Limits }\end{array}$ & Chi-Square & Pr > Chi-Sq \\
\hline Intercept & -0.3879 & 0.0178 & -0.4229 & -0.353 & 472.47 & $<.0001$ \\
\hline Dummy Access to Road & 0.1077 & 0.0059 & 0.0962 & 0.1192 & 336.26 & $<.0001$ \\
\hline Distance to market & -0.018 & 0.0003 & -0.0187 & -0.0173 & 2673.26 & $<.0001$ \\
\hline Electricity dummy & 0.2431 & 0.0075 & 0.2285 & 0.2577 & 1064.67 & $<.0001$ \\
\hline Access to credit dummy & 0.0297 & 0.0035 & 0.0229 & 0.0366 & 72.83 & $<.0001$ \\
\hline H Head's education (years) & 0.0885 & 0.0009 & 0.0866 & 0.0903 & 9077.28 & $<.0001$ \\
\hline Dependents ratio & -0.2029 & 0.0007 & -0.2043 & -0.2014 & 74556.8 & $<.0001$ \\
\hline Land area detained & 0.1733 & 0.0017 & 0.1701 & 0.1766 & 10893.6 & $<.0001$ \\
\hline Livestock heads detained & 0.1304 & 0.0006 & 0.1291 & 0.1317 & 41019.7 & $<.0001$ \\
\hline Occupation: Farmers only & 0.0663 & 0.0066 & 0.0534 & 0.0793 & 100.31 & $<.0001$ \\
\hline Occupation: Agri wage worker & -0.0851 & 0.0099 & -0.1046 & -0.0657 & 73.77 & $<.0001$ \\
\hline $\begin{array}{l}\text { Occupation: Non-farm wage } \\
\text { worker }\end{array}$ & 0.9515 & 0.0097 & 0.9325 & 0.9705 & 9678.01 & $<.0001$ \\
\hline $\begin{array}{l}\text { Occupation: Non-farm self } \\
\text { employed }\end{array}$ & 0.9175 & 0.0122 & 0.8936 & 0.9415 & 5641.28 & $<.0001$ \\
\hline Dummy Province: Butare & -0.413 & 0.0088 & -0.4302 & -0.3958 & 2219.65 & $<.0001$ \\
\hline Dummy Province: Byumba & -0.1436 & 0.0089 & -0.1611 & -0.1261 & 258.35 & $<.0001$ \\
\hline Dummy Province: Cyangugu & -0.0079 & 0.0093 & -0.0262 & 0.0104 & 0.72 & 0.3973 \\
\hline Dummy Province: Gikongoro & -0.6147 & 0.0095 & -0.6334 & -0.5961 & 4172.71 & $<.0001$ \\
\hline Dummy Province: Gisenyi & 0.3932 & 0.0092 & 0.3752 & 0.4112 & 1835.89 & $<.0001$ \\
\hline Dummy Province: Gitarama & 0.087 & 0.0087 & 0.0699 & 0.1041 & 99.07 & $<.0001$ \\
\hline Dummy Province: Kibungo & 0.2772 & 0.009 & 0.2596 & 0.2949 & 944.15 & $<.0001$ \\
\hline Dummy Province: Kibuye & -0.2396 & 0.0098 & -0.2589 & -0.2203 & 593.72 & $<.0001$ \\
\hline Dummy Province: Kigali & -0.3153 & 0.0086 & -0.3321 & -0.2984 & 1342.69 & $<.0001$ \\
\hline Dummy Province: Ruhengeri & -0.2806 & 0.0087 & -0.2977 & -0.2635 & 1034.2 & $<.0001$ \\
\hline
\end{tabular}

Note:

Excluded categories: "No occupation" and "other occupation"; "Kigali City" and "Umutara" 
Table 3. Source of Household Income

\begin{tabular}{|c|c|c|c|}
\hline Income Category & Rural & Urban & National \\
\hline Labor Market Income & $42.5 \%$ & $83.6 \%$ & $58.6 \%$ \\
\hline Agriculture/Livestock/Sylvic/Fishing/Hunting & $7.9 \%$ & $0.8 \%$ & $5.1 \%$ \\
\hline Manufacturing Industries & $3.3 \%$ & $6.0 \%$ & $4.4 \%$ \\
\hline Buildings and Public Works & $3.1 \%$ & $5.6 \%$ & $4.1 \%$ \\
\hline Commerce & $7.3 \%$ & $20.3 \%$ & $12.4 \%$ \\
\hline Services a la Collectivite & $16.0 \%$ & $31.3 \%$ & $22.0 \%$ \\
\hline Other Sectors & $5.0 \%$ & $19.6 \%$ & $10.7 \%$ \\
\hline Agricultural Income & $41.6 \%$ & $0.7 \%$ & $25.5 \%$ \\
\hline Industrial Crops: & $2.9 \%$ & $0.0 \%$ & $1.8 \%$ \\
\hline Coffee & $2.4 \%$ & $0.0 \%$ & $1.5 \%$ \\
\hline Tea & $0.4 \%$ & $0.0 \%$ & $0.3 \%$ \\
\hline Food Crops: & $33.2 \%$ & $0.4 \%$ & $20.3 \%$ \\
\hline Beans & $3.6 \%$ & $0.0 \%$ & $2.2 \%$ \\
\hline Sorghum & $2.2 \%$ & $0.0 \%$ & $1.3 \%$ \\
\hline Cassava & $3.7 \%$ & $0.1 \%$ & $2.3 \%$ \\
\hline Sweet Potatoes & $2.6 \%$ & $0.0 \%$ & $1.6 \%$ \\
\hline Livestock Income: & $5.5 \%$ & $0.3 \%$ & $3.4 \%$ \\
\hline Cattle & $3.5 \%$ & $0.3 \%$ & $2.2 \%$ \\
\hline Sheep & $1.2 \%$ & $0.0 \%$ & $0.7 \%$ \\
\hline Transfers & $8.9 \%$ & $3.6 \%$ & $6.8 \%$ \\
\hline Other Income & $7.0 \%$ & $12.1 \%$ & $9.0 \%$ \\
\hline Total Income & $100.0 \%$ & $100.0 \%$ & $100.0 \%$ \\
\hline
\end{tabular}

Note: All farm households in urban provinces are considered rural

Table 4. Percentage of Farmers Growing Coffee, by Income Decile

\begin{tabular}{|l|c}
\hline Expenditure decile & \% of farmers growing coffee \\
Poorest decile & 8.4 \\
2nd decile & 9.7 \\
3rd decile & 10.3 \\
4th decile & 13.5 \\
5th decile & 12.0 \\
6th decile & 11.8 \\
7th decile & 13.6 \\
8th decile & 10.4 \\
9th decile & 8.7 \\
Richest decile & 1.5 \\
Total & 10.0 \\
\hline
\end{tabular}


Table 5. Share of Income from Coffee, by Province

Province

Butare

Byumba

Cyangugu

Gikongoro

Gisenyi

Gitarama

Kibungo

Kibuye

Kigali Ngali

Kigali Town

Ruhengeri

Umutara

Source: Rwanda EICV 2001
Share of Coffee in Total Income (\%)

3.7

2.5

13.9

5.5

6.0

6.7

2.6

9.0

9.2

1.2

2.4

0.0

Table 6. Impact of a 50 Percent Reduction of Rural Transport Costs on Incomes

\begin{tabular}{lcccccc}
\hline Effect on: & $\begin{array}{c}\text { Reduction transport } \\
\text { cost }\end{array}$ & $\begin{array}{c}\text { pass- } \\
\text { through }\end{array}$ & $\begin{array}{c}\text { Headcount } \\
\text { index }\end{array}$ & Change & $\begin{array}{c}\text { Poverty } \\
\text { Gap }\end{array}$ & Change \\
coffee farmers & 0 & 0 & 41.97 & & 0.136 & \\
coffee farmers & $50 \%$ & 1 & 39.60 & $-5.65 \%$ & 0.126 & $-7.12 \%$ \\
coffee farmers & $50 \%$ & 0.5 & 41.31 & $-1.57 \%$ & 0.131 & $-3.72 \%$ \\
National & 0 & 0 & 42.92 & & 0.157 & \\
National & $50 \%$ & 1 & 42.69 & $-0.53 \%$ & 0.156 & $-0.59 \%$ \\
National & $50 \%$ & 0.5 & 42.86 & $-0.15 \%$ & 0.157 & $-0.31 \%$ \\
\hline
\end{tabular}

Source: Computed by authors from EICV data 


\section{WPS3784}

Table 7. Distributional and Regional Impact of a 50 percent Fall in Transport Costs among Coffee Farmers (assuming 100 pass-through)

\begin{tabular}{rcc}
\hline & Share of coffee in total income & Change in real income \\
\hline Expenditure decile & & \\
Poorest decile & $6.70 \%$ & $1.34 \%$ \\
2 nd & $8.23 \%$ & $1.65 \%$ \\
3rd & $7.16 \%$ & $1.43 \%$ \\
4 th & $14.42 \%$ & $2.88 \%$ \\
5 th & $4.33 \%$ & $0.87 \%$ \\
6 th & $5.06 \%$ & $1.01 \%$ \\
7 th & $5.04 \%$ & $1.01 \%$ \\
8 th & $3.09 \%$ & $0.62 \%$ \\
9 th & $4.16 \%$ & $0.83 \%$ \\
Richest & $1.79 \%$ & $0.36 \%$ \\
Butare & $3.72 \%$ & \\
Province & $2.51 \%$ & $0.74 \%$ \\
Cyanba & $13.89 \%$ & $0.50 \%$ \\
Gikongoro & $5.50 \%$ & $2.78 \%$ \\
Gisenyi & $6.02 \%$ & $1.10 \%$ \\
Gitarama & $2.68 \%$ & $1.20 \%$ \\
Kibungo & $2.59 \%$ & $0.54 \%$ \\
Kibuye & $9.03 \%$ & $0.52 \%$ \\
Kigali Ngali & $9.22 \%$ & $1.81 \%$ \\
Ville de Kigali & $1.15 \%$ & $1.84 \%$ \\
Ruhengeri & $2.42 \%$ & $0.23 \%$ \\
\hline Umutara & $0.00 \%$ & $0.48 \%$ \\
\hline & & $0.00 \%$ \\
\hline
\end{tabular}


WPS3784

Table 8. Composition of household budget by Province

\begin{tabular}{|c|c|c|c|c|c|c|c|}
\hline Province & Butare & Byumba & Cyangugu & Gikongoro & Gisenyi & Gitarama & Kibungo \\
\hline Food Bought & $42.2 \%$ & $48.7 \%$ & $54.4 \%$ & $45.8 \%$ & $49.5 \%$ & $42.8 \%$ & $39.8 \%$ \\
\hline Dry beans & $5.4 \%$ & $8.5 \%$ & $3.4 \%$ & $10.6 \%$ & $7.2 \%$ & $4.4 \%$ & $2.5 \%$ \\
\hline Irish Potatoes & $2.4 \%$ & $4.2 \%$ & $1.9 \%$ & $4.8 \%$ & $7.4 \%$ & $4.6 \%$ & $1.6 \%$ \\
\hline Rice & $3.8 \%$ & $2.0 \%$ & $4.1 \%$ & $1.5 \%$ & $1.7 \%$ & $2.7 \%$ & $2.9 \%$ \\
\hline Beef & $1.4 \%$ & $1.7 \%$ & $2.6 \%$ & $0.8 \%$ & $2.0 \%$ & $2.1 \%$ & $1.7 \%$ \\
\hline Beverages & $3.4 \%$ & $5.5 \%$ & $3.4 \%$ & $4.0 \%$ & $5.8 \%$ & $2.5 \%$ & $5.1 \%$ \\
\hline Energy & $2.7 \%$ & $4.7 \%$ & $3.7 \%$ & $2.2 \%$ & $3.1 \%$ & $2.6 \%$ & $3.3 \%$ \\
\hline Housing & $4.6 \%$ & $0.9 \%$ & $1.3 \%$ & $2.1 \%$ & $2.3 \%$ & $0.5 \%$ & $1.9 \%$ \\
\hline Cleaning & $6.7 \%$ & $6.0 \%$ & $6.7 \%$ & $5.8 \%$ & $6.8 \%$ & $6.4 \%$ & $7.5 \%$ \\
\hline Leisure & $1.2 \%$ & $0.9 \%$ & $1.9 \%$ & $1.1 \%$ & $1.8 \%$ & $1.1 \%$ & $0.8 \%$ \\
\hline Clothing & $6.8 \%$ & $6.1 \%$ & $4.8 \%$ & $6.8 \%$ & $7.2 \%$ & $7.3 \%$ & $10.4 \%$ \\
\hline Education & $2.7 \%$ & $3.0 \%$ & $4.0 \%$ & $4.4 \%$ & $2.4 \%$ & $4.7 \%$ & $3.9 \%$ \\
\hline Health & $1.4 \%$ & $0.9 \%$ & $1.5 \%$ & $0.6 \%$ & $0.9 \%$ & $1.4 \%$ & $1.2 \%$ \\
\hline Transport & $3.0 \%$ & $1.8 \%$ & $1.1 \%$ & $0.6 \%$ & $2.2 \%$ & $1.3 \%$ & $2.8 \%$ \\
\hline Other & $25.2 \%$ & $21.4 \%$ & $17.3 \%$ & $26.6 \%$ & $17.9 \%$ & $29.5 \%$ & $23.3 \%$ \\
\hline Total Consumption & $100.0 \%$ & $100.0 \%$ & $100.0 \%$ & $100.0 \%$ & $100.0 \%$ & $100.0 \%$ & $100.0 \%$ \\
\hline
\end{tabular}

\begin{tabular}{|c|c|c|c|c|c|c|}
\hline Province & Kibuye & Kigali & Kigali City & Ruhengeri & Umutara & National \\
\hline Food Bought & $53.7 \%$ & $46.0 \%$ & $33.9 \%$ & $46.8 \%$ & $38.7 \%$ & $41.8 \%$ \\
\hline Dry beans & $12.9 \%$ & $6.8 \%$ & $1.7 \%$ & $7.2 \%$ & $4.2 \%$ & $4.6 \%$ \\
\hline Irish Potatoes & $6.5 \%$ & $5.3 \%$ & $2.5 \%$ & $7.5 \%$ & $1.9 \%$ & $3.8 \%$ \\
\hline Rice & $1.4 \%$ & $2.3 \%$ & $3.0 \%$ & $1.4 \%$ & $2.6 \%$ & $2.7 \%$ \\
\hline Beef & $1.0 \%$ & $1.2 \%$ & $2.8 \%$ & $1.2 \%$ & $1.1 \%$ & $2.0 \%$ \\
\hline Beverages & $4.6 \%$ & $3.6 \%$ & $2.9 \%$ & $3.3 \%$ & $4.7 \%$ & $3.7 \%$ \\
\hline Energy & $2.8 \%$ & $2.9 \%$ & $3.6 \%$ & $2.3 \%$ & $4.0 \%$ & $3.3 \%$ \\
\hline Housing & $2.2 \%$ & $3.6 \%$ & $9.0 \%$ & $1.4 \%$ & $0.8 \%$ & $4.5 \%$ \\
\hline Cleaning & $5.9 \%$ & $6.4 \%$ & $6.6 \%$ & $4.7 \%$ & $11.9 \%$ & $6.6 \%$ \\
\hline Leisure & $1.2 \%$ & $1.0 \%$ & $1.7 \%$ & $0.7 \%$ & $1.2 \%$ & $1.4 \%$ \\
\hline Clothing & $4.4 \%$ & $5.3 \%$ & $3.3 \%$ & $5.9 \%$ & $5.9 \%$ & $5.4 \%$ \\
\hline Education & $2.9 \%$ & $5.9 \%$ & $3.7 \%$ & $3.3 \%$ & $4.3 \%$ & $3.8 \%$ \\
\hline Health & $3.0 \%$ & $1.7 \%$ & $1.3 \%$ & $1.0 \%$ & $2.1 \%$ & $1.3 \%$ \\
\hline Transport & $1.0 \%$ & $3.0 \%$ & $5.1 \%$ & $1.7 \%$ & $2.2 \%$ & $3.1 \%$ \\
\hline Other & $18.3 \%$ & $20.5 \%$ & $28.9 \%$ & $28.9 \%$ & $24.0 \%$ & $25.2 \%$ \\
\hline Total Consumption & $100.0 \%$ & $100.0 \%$ & $100.0 \%$ & $100.0 \%$ & $100.0 \%$ & $100.0 \%$ \\
\hline
\end{tabular}


Table 9. Impact of Quality-Driven Price Premium

\begin{tabular}{lcccccc}
\hline $\begin{array}{l}\text { Simulation: doubling } \\
\text { coffee price: }\end{array}$ & $\begin{array}{c}\text { Headcount } \\
\text { PO change }\end{array}$ & $\begin{array}{c}\text { Poverty } \\
\text { in P0 }\end{array}$ & $\begin{array}{c}\text { Change in } \\
\text { gap (P1) }\end{array}$ & $\begin{array}{c}\text { \%1 change in } \\
\text { expenditure }\end{array}$ & $\begin{array}{c}\text { \% change } \\
\text { in income }\end{array}$ \\
baseline coffee farmers & $\mathbf{4 1 . 8 8}$ & $\mathbf{0 . 0 0 \%}$ & $\mathbf{0 . 1 3 5}$ & $\mathbf{0 . 0 0 \%}$ & $\mathbf{0 . 0 0 \%}$ & $\mathbf{0 . 0 0 \%}$ \\
50\% of all coffee farmers & 39.86 & $-4.82 \%$ & 0.124 & $-8.25 \%$ & $2.49 \%$ & $4.85 \%$ \\
all large coffee farmers & 41.15 & $-1.74 \%$ & 0.131 & $-2.93 \%$ & $1.34 \%$ & $3.15 \%$ \\
all medium coffee farmers & 40.77 & $-2.65 \%$ & 0.132 & $-2.79 \%$ & $0.87 \%$ & $1.92 \%$ \\
all medium and large & 40.05 & $-4.37 \%$ & 0.128 & $-5.72 \%$ & $2.21 \%$ & $5.07 \%$ \\
coffee farmers & & & & & & \\
small coffee farmers & 39.23 & $-6.33 \%$ & 0.120 & $-11.08 \%$ & $2.93 \%$ & $4.85 \%$ \\
\hline
\end{tabular}

Source: Computed by authors from EICV data

Table 10. Determinants of the Probability of Being a Coffee Farmer (propensity score)

\begin{tabular}{|c|c|c|c|c|c|c|c|}
\hline \multirow{2}{*}{\begin{tabular}{|l|} 
Parameter \\
Intercept \\
\end{tabular}} & \multirow{2}{*}{\begin{tabular}{|c|} 
DF \\
1
\end{tabular}} & \multirow{2}{*}{\begin{tabular}{|c|} 
Estimate \\
-3.1209 \\
\end{tabular}} & \multirow{2}{*}{$\begin{array}{c}\begin{array}{c}\text { Standard } \\
\text { Error }\end{array} \\
0.0318\end{array}$} & \multicolumn{2}{|c|}{$\begin{array}{c}\text { Wald 95\% Confidence } \\
\text { Limits }\end{array}$} & \multirow{2}{*}{$\begin{array}{c}\begin{array}{c}\text { Chi- } \\
\text { Square }\end{array} \\
9651.42\end{array}$} & \multirow{2}{*}{\begin{tabular}{|c|} 
Pr $>$ ChiSq \\
$<.0001$
\end{tabular}} \\
\hline & & & & -3.1832 & -3.0586 & & \\
\hline Distance to road & 1 & -0.0353 & 0.0028 & -0.0407 & -0.0298 & 158.7 & $<.0001$ \\
\hline Access to electricity & 1 & 1.0688 & 0.0372 & 0.9959 & 1.1418 & 824.84 & $<.0001$ \\
\hline $\begin{array}{l}\text { Extension services } \\
\text { dummy }\end{array}$ & 1 & 0.1843 & 0.0049 & 0.1747 & 0.1938 & 1439.03 & $<.0001$ \\
\hline Head's Education & 1 & 0.023 & 0.0014 & 0.0202 & 0.0258 & 257.34 & $<.0001$ \\
\hline Dependency ratio & 1 & 0.0441 & 0.0011 & 0.042 & 0.0462 & 1687.25 & $<.0001$ \\
\hline Land area & 1 & 0.0345 & 0.0012 & 0.0321 & 0.037 & 763.17 & $<.0001$ \\
\hline Livestock heads & 1 & 0.0058 & 0.0004 & 0.0051 & 0.0066 & 234.77 & $<.0001$ \\
\hline Head is male dummy & 1 & 0.1184 & 0.0058 & 0.1069 & 0.1298 & 411.64 & $<.0001$ \\
\hline Use fertilizer dummy & 1 & 0.1508 & 0.0048 & 0.1414 & 0.1602 & 984.59 & $<.0001$ \\
\hline Dummy Butare & 1 & 1.7102 & 0.0247 & 1.6617 & 1.7587 & 4779.86 & $<.0001$ \\
\hline Dummy Byumba & 1 & 1.1653 & 0.0251 & 1.1162 & 1.2145 & 2158.49 & $<.0001$ \\
\hline Dummy Cyangugu & 1 & 2.5895 & 0.0252 & 2.5401 & 2.639 & 10529.5 & $<.0001$ \\
\hline Dummy Gikongoro & 1 & 1.4111 & 0.0253 & 1.3615 & 1.4606 & 3114.6 & $<.0001$ \\
\hline Dummy Gisenyi & 1 & 1.3244 & 0.0253 & 1.2748 & 1.3739 & 2740.1 & $<.0001$ \\
\hline Dummy Gitarama & 1 & 1.5732 & 0.0246 & 1.5249 & 1.6214 & 4078.33 & $<.0001$ \\
\hline Dummy Kibungo & 1 & 1.2965 & 0.0249 & 1.2477 & 1.3453 & 2712.76 & $<.0001$ \\
\hline Dummy Kibuye & 1 & 1.3999 & 0.0255 & 1.35 & 1.4498 & 3023.54 & $<.0001$ \\
\hline Dummy Kigali & 1 & 1.0657 & 0.0255 & 1.0158 & 1.1156 & 1752.61 & $<.0001$ \\
\hline Dummy Ruhengeri & 1 & 0.2822 & 0.0273 & 0.2288 & 0.3357 & 107.17 & $<.0001$ \\
\hline
\end{tabular}




\section{WPS3784}

Table 11. Income Gains from Switching from Subsistence to Coffee Farming

\begin{tabular}{lcc}
\hline Sample: all household heads & $\begin{array}{c}\text { Matching } \\
\text { method: } \\
\text { Epanechnikov }\end{array}$ & $\begin{array}{c}\text { Matching } \\
\text { method: } \\
\text { Normal kernel }\end{array}$ \\
\hline Observed average agricultural income coffee farmer & 99876.3 & 99876.3 \\
Observed average agricultural income subsistence farmer & 74072.8 & 74072.8 \\
Subsistence farmers' agricultural income had they participated & 91256.2 & 96267.1 \\
Gain from participation in coffee farming & 17183.4 & 22194.4 \\
& & $30.0 \%$ \\
Proportionate change in subsistence farmers' income & $23.2 \%$ & $-27 \%$ \\
Impact on the headcount level & $-24.9 \%$ & $-12.9 \%$ \\
Impact on the poverty gap & $-12.5 \%$ & \\
& & \\
Total sample (household heads)1 & 2753 & \\
Number of people that switch and gain & 1073 & \\
Percentage of people that switch and gain & $39 \%$ & \\
\hline
\end{tabular}

Note:Missing values are excluded, so the sample size reported here is smaller than the actual number of head farmers

* = Statistically significant as established through bootstrapping. 